\title{
RESENHA
}

\section{ESSA ESTRANHA INSTITUIÇÃO CHAMADA LITERATURA}

\author{
Silvana Nascimento Lianda ${ }^{1}$ \\ Tássia Borges do Nascimento ${ }^{2}$ \\ Jailma dos Santos Pedreira Moreira ${ }^{3}$
}

\section{Referência da obra resenhada:}

DERRIDA, Jacques. Essa estranha instituição chamada literatura: uma entrevista com Jacques Derrida. Trad. Marileide Dias Esqueda. Belo Horizonte: UFMG, 2014.

Nascido na Argélia, em 1930, Jacques Derrida foi um dos pensadores franceses mais influentes, controversos e conhecidos internacionalmente, em particular nos Estados Unidos. Lecionou nas universidades de Harvard, Yale e John Hopkins. Na França, ensinou na Sorbonne e na Escola Normal Superior. Derrida foi precursor de uma reflexão crítica sobre a filosofia e seu ensino e o criador do método chamado de desconstrução. Isso o levou a criar, em 1983, o Colégio Internacional de Filosofia, presidido por ele até 1985. Derrida estive no Brasil três vezes: em 1995, 2001, e em agosto de 2004, véspera da sua morte que ocorreu em Paris, no dia 8 de outubro de 2004.

O livro Essa estranha instituição chamada literatura: uma entrevista com Jacques Derrida é formado por uma apresentação, que ocupa aproximadamente um terço da obra, e uma entrevista sobre literatura, composta por dezoito questões. A entrevista foi realizada por Derek Attridge, em inglês, e as respostas foram dadas em francês por Jacques Derrida, em abril de 1989, em Laguna Beach, na Califórnia. A tradução para a língua inglesa foi

\footnotetext{
${ }^{1}$ Mestranda do programa em Crítica Cultural, da Universidade do Estado da Bahia (UNEB/Campus II). Endereço eletrônico: sil_lianda@hotmail.com.

${ }^{2}$ Mestranda do programa em Crítica Cultural da Universidade do Estado da Bahia (UNEB/Campus II). Endereço eletrônico: tassia_borgesss@hotmail.com.

${ }^{3}$ Doutora pela Universidade Federal da Bahia (UFBA), docente do programa em Crítica Cultural da Universidade do Estado da Bahia (UNEB/Campus II).Endereço eletrônico: jailmapedreira@uol.com.br.
} 
realizada por Geoffrey Bennington e Rachel Bowlby e a tradução para o português por Marileide Dias Esqueda.

A introdução foi escrita por Evandro Nascimento, que também revisou todo o livro, e dividida em cinco tópicos. No primeiro, intitulado “Questões de princípio”, ele narra como no início dos anos de 1990, como aluno inscrito nos seminários de Jacques Derrida, teve o primeiro contato com a entrevista. Explica que na época Derrida lhe trouxe o livro Acts of Literature, recém publicado e organizado por Derek Attridge, contendo a entrevista depois convertida no livro Derrida e a Literatura. Comenta que suas discussões com Derrida eram em torno do sentido e da essência da literatura e como essa entrevista modificaria os rumos de seu projeto de pesquisa, sendo que Derrida e a literatura se tornariam o seu objeto de investigações. Cita que a entrevista foi realizada em 1989 e publicada pela primeira vez três anos depois e afirma que nela encontram-se ferramentas potentes para pensar as conflituosas relações entre discurso literário e discurso filosófico. Explica como a entrevista original era bilíngue, uma vez que Derrida respondia em francês a perguntas formuladas em inglês, por Attridge.

No segundo tópico: “Natureza e função da Literatura”, fala acerca da atividade de tradução que o faz indagar o que é ou não compreensível quando transplantado de uma língua para outra. Afirma que sempre restarão rastros do idioma original e que esse princípio é indicativo do próprio literário enquanto escritura e leitura. Defende que a literatura nunca se autoidentifica de todo a seu próprio discurso, mas também não se identifica integralmente a nenhum outro discurso. Mas, paradoxalmente, ela precisa abrir-se ao mundo para sobreviver, dialogando com outras produções artísticas e culturais e com a própria história. E assim, não pode haver natureza e função da literatura em si já que esta não tem essência previamente estabelecida, sendo que o reconhecido como literatura deriva de convenções estabelecidas do lado de quem escreve. Assim, a particularidade do literário é se tratar de uma forma histórica a partir da qual o poder "dizer tudo" que o acompanha servem para pensar o significado de deixar rastros.

No terceiro tópico: “Literatura e Democracia”, Nascimento comenta que a desconstrução não se reduz nem ao território da filosofia, nem da 
literatura e na entrevista está expresso o desejo de que ela também não fosse um texto nem literário nem filosófico. O Dizer tudo do literário está relacionado com o advento da democracia moderna, uma vez que o dizer tudo é transpor os interditos. A literatura é, assim, uma instituição que tende a extrapolar a instituição, uma vez que todas elas se constroem segundo determinadas regras que delimitam o que pode ou não ser dito. A categoria de uma literatura pensante, nesse sentido, ajuda a repensar essas delimitações institucionais a partir da liberdade democrática do dizer tudo.

No quarto tópico, intitulado "Silêncio, Segredo e Contratempo", explica que em ficção um segredo pode ser velado no ato de revelar outra história, pois os enunciados literários têm no mínimo uma dupla face, de modo que o dizer não exclui o calar. Cita um momento da entrevista no qual Derrida respondendo sobre o texto que escreveu a respeito da peça de Shakespeare aborda a relação entre acaso e destino, envolvendo o que chama de contratempo. Assim, a existência seria um jogo entre acaso e determinação, visto que o aleatório interfere no decurso do próprio tempo. Além disso, a leitura e a escrita atendem a uma injunção do acaso e da necessidade.

No quinto e último tópico da introdução, intitulado "Cursos, Percursos e Associações”, Evandro Nascimento encerra a introdução refletindo acerca da importância do pensamento derridiano e dos estudos de desconstrução. Afirma a possibilidade de se pensar uma associação enquanto um coletivo que signifique o desejo de encontro, a despeito ou por causa dos acidentes de percurso, de seus inúmeros contratempos. Uma coletividade singular e plural, mas que se pense sempre como sem fundamento único, uma associação descentrada, como fruto de um esforço de reflexão coletiva.

Na sequência, passa a ser apresentada a entrevista a Jacques Derrida realizada por Derek Attridge. Ela é iniciada a partir do questionamento de Attridge acerca do fato dos textos de Derrida serem preferencialmente filosóficos, embora este afirme ter a literatura como primeiro interesse. No entanto, o pensador não responde acerca de colocar a literatura em primeiro lugar e passa a inquirir o sentido de literatura e a impressão da liberdade que ela aparenta possuir ao poder falar de tudo. Assim, defende ser essa liberdade uma arma política, mas com o risco de se deixar neutralizar como ficção, e 
ressalta o poder dela de se recusar a responder pelo seu pensamento ou por sua escritura, diante de poderes constituídos, como uma forma elevada de responsabilidade. Por outro lado, a questão filosófica lhe parecia necessária por pressentir haver uma inocência, e talvez até impotência, na literatura. Nesse sentido, cita seu interesse por uma forma de literatura que carregava uma questão sobre ela própria e por um tipo filosófico de atividade que interrogava a relação entre fala e escrita.

A propósito da distinção feita pelo pensador entre literatura e poesia, segundo ele, o conjunto de convenções que estabeleceu a literatura, na modernidade, não era indispensável para a circulação de obras poéticas. Já a respeito de Derrida ter escrito mais sobre textos literários, em comparação a textos filosóficos, e sendo estes textos não tradicionais no uso da linguagem e das convenções, Attridge indaga o porquê dessa escolha e a necessidade dela. $\mathrm{O}$ entrevistado rebate que escreve a partir de provocações, as quais se referem, frequentemente, aos escritores contemporâneos. Explica serem textos escritos numa experiência crítica, uma espécie de retorno à instituição literária, por perguntarem a respeito de seu conceito, origem e uso. Alega ser levado com mais facilidade a textos sensíveis à crise dessa instituição, mesmo considerando sua estrutura paradoxal, em que o seu início é ao mesmo tempo o seu fim, começando pela sua ausência de especificidade e de objeto. Além disso, acrescenta serem textos que dão forma teórica, filosófica ou sociológica para a literatura, já que analisam, questionam e transformam essa instituição sem instituição.

O entrevistador interroga sobre a chance de textos literários operarem contra o modelo dominante de literatura. O pensador ressalta a possibilidade de se fazer uma leitura não transcendente de qualquer tipo de texto e que nenhum é literário em si, uma vez que a literariedade não é uma propriedade intrínseca do texto. Na sequência, Attridge menciona o fato de alguns teóricos e críticos literários defenderem que um texto é literário se resiste a uma leitura transcendental. O filósofo aponta que nenhum texto resiste e explica que a literatura nunca se apresenta como tal, pois se ela falasse apenas de si, se anularia de imediato. Além disso, cita haver uma dificuldade em definir a questão da literatura dissociando-a da essência da linguagem e ela 
é o lugar dessa dificuldade, sendo nesse lugar que seu interesse por ela se cruza com seu interesse pela filosofia ou metafísica.

Acerca da literatura ser dominada por pressupostos metafísicos e a necessidade de uma distinção entre ela e a crítica literária, o entrevistado assegura que tais pressupostos podem habitá-la de várias formas que precisam ser distinguidas cuidadosamente. E completa que a boa crítica literária implica uma experiência inventiva da linguagem, uma inscrição do ato de leitura no campo do texto lido, sendo que esse texto nunca se deixa ser completamente objetivado. Já no tocante à tradição dessa crítica se mostrar tão governada pelos pressupostos metafísicos quanto à filosofia e mais que os textos literários, ele concorda, ressaltando, entretanto, que tal crítica não é governada apenas pelos pressupostos metafísicos, bem como um texto também não o é. Afirma haver hierarquias e relações de forças tanto na crítica literária, quanto na filosofia, porém, a crítica tendeu a ser mais filosófica que a literatura por querer ser teórica. Indagado se vê como tarefa importante, dos críticos literários, a solidariedade histórica da literatura com a metafísica, Derrida rebate que esse elo deve ser questionado e deslocado, mas a solidariedade histórica deve ser lembrada, sendo essa uma tarefa importante para esses críticos e para o escritor, já que quem escreve deve estar inquieto com relação ao passado da cultura em geral.

A respeito da literatura colocar o falocentrismo e o logocentrismo em questão, o entrevistado aponta a crítica literária feminista como desconstrutora do que se anuncia na figura de falocentrismo. Por outro lado, defende que, às vezes, os textos mais falocêntricos em sua temática podem produzir efeitos desconstrutores contra o próprio falocentrismo. O entrevistador indaga se um texto literário que põe em questão o logocentrismo age do mesmo modo em relação ao falocentrismo e o filósofo confirma, embora apresente ambos como indissociáveis, sendo o falogocentrismo uma coisa única, mas que exige estratégias diferenciadas. Segundo ele, algumas feministas não compreendem que sem uma leitura exigente dessa articulação, o discurso feminista se arrisca a reproduzir aquilo que critica.

Na sequência, em resposta a escrever acerca de Samuel Beckett como um projeto futuro, o interrogado declara se sentir próximo demais dele e que o 
tem evitado por conta dessa identificação. Explica serem os textos desse autor, ao mesmo tempo, muito próximos e distantes de si para que possa se sentir capaz de responder a eles. Attridge problematiza se a escritura de Beckett já é tão desconstrutora ou autodesconstrutora a ponto de não restar muito a fazer e Derrida admite que sim e completa que a obra desse autor é o que resta quando a temática está exaurida.

No tocante à escolha da peça Romeu e Julieta, de Shakespeare, para a escrita de uma leitura proposta por Derrida e se a citada peça apresenta problemas específicos para tal leitura, o filósofo aponta que não a leu como um texto do século XVI e privilegiou os motivos do contratempo e da anacronia. Em relação aos problemas que apresenta, garante que seria preciso reconstituir o elemento histórico de uma peça como essa e complementa que não há história sem iterabilidade e esta permite aos rastros continuarem a funcionar na ausência do contexto geral ou de alguns elementos do contexto.

O entrevistador pergunta se a crítica literária tradicional revela a unicidade e singularidade do texto que comenta, se em seu trabalho com textos literários ele tem esse objetivo e se é possível falar da unicidade de um texto separada do ato histórico da leitura. Derrida rebate que, por um lado, uma obra é sempre singular, acontece apenas uma vez e essa unicidade da instituição lhe parece completamente histórica. Por outro lado, a singularidade absoluta nunca é fechada, dada como um fato ou um objeto.

Acerca da possível especificidade da literatura, Derrida alerta que é necessário discernir o fenômeno historicamente determinado das convenções sociais e das instituições que dão lugar à literatura, sendo que ela consiste em transgredir e transformar, em produzir formas discursivas. Nesse sentido, interpelado a respeito da existência da literatura, afirma não haver nenhuma essência garantida para a mesma e, por isso, nunca se encontrará a própria literatura, apenas alguns traços que ela compartilha ou toma emprestado e que se pode encontrar em outros textos.

Encerrando a entrevista, a última questão aplicada se refere ao desejo expresso por Derrida de escrever um texto que não seria nem filosofia, nem literatura. Assim, indagado sobre quem seria capaz de ler tal texto, o pensador explica que de fato sonha com uma escritura que não seria nem 
RESENHA

ESSA ESTRANHA INSTITUIÇÂO CHAMADA LITERATURA

filosofia, nem literatura, com uma instituição sem precedente, sem préinstituição. Conclui apontando que o leitor capaz de lê-lo ainda não existe, uma vez que ele seria instruído e construído pela obra, ou seja, a obra se tornaria uma instituição formadora de seus próprios leitores. 
